\title{
17DD yellow fever vaccine
} A double blind, randomized clinical trial of immunogenicity and safety on a dose-response study

Reinaldo M. Martins, ${ }^{1, *}$ Maria de Lourdes S. Maia, ${ }^{1}$ Roberto Henrique G. Farias, ${ }^{1}$ Luiz Antonio B. Camacho, ${ }^{2}$ Marcos S.Freire, ${ }^{1}$ Ricardo Galler, ${ }^{1}$ Anna Maya Yoshida Yamamura, ${ }^{1}$ Luiz Fernando C. Almeida, ${ }^{1}$ Sheila Maria B. Lima, ${ }^{1}$ Rita Maria R. Nogueira, ${ }^{3}$ Gloria Regina S. Sá,, Darcy A. Hokama, ${ }^{1}$ Ricardo de Carvalho, ${ }^{1}$ Ricardo Aguiar V. Freire, ${ }^{4}$ Edson Pereira Filho, ${ }^{4}$ Maria da Luz Fernandes Leal' and Akira Homma'

'Bio-Manguinhos, Fiocruz; Rio de Janeiro, Brazil; '²scola Nacional de SaúdePública, Fiocruz; Rio de Janeiro, Brazil; ${ }^{3}$ Instituto Oswaldo Cruz, Fiocruz; Rio de Janeiro, Brazil; ${ }^{4}$ Instituto de Biologia do Exército; Rio de Janeiro, Brazil

Keywords: yellow fever vaccine, immunogenicity, safety, reactogenicity, dose-response study, viremia, dengue interactions, Bio-Manguinhos/Fiocruz

Abbreviations: CI, confidence interval; GMT, geometric mean titer; IU, international units; mIU, milli international unit; MLD50, mean lethal dose for $50 \%$ of a mice lot; $\mathrm{MoH}$, Ministry of Health; PFU, plaque forming unit; PRNT, plaque reduction neutralization test; RNA, ribonucleic acid; RT-PCR, real time polymerase chain reaction; WHO, World Health Organization; YF, yellow fever; YFV, yellow fever vaccine; 17DD-YFV, 17DD yellow fever vaccine

Objective: To verify if the Bio-Manguinhos 17DD yellow fever vaccine (17DD-YFV) used in lower doses is as immunogenic and safe as the current formulation.

Results: Doses from 27,476 IU to 587 IU induced similar seroconversion rates and neutralizing antibodies geometric mean titers (GMTs). Immunity of those who seroconverted to YF was maintained for 10 mo. Reactogenicity was low for all groups.

Methods: Young and healthy adult males $(n=900)$ were recruited and randomized into 6 groups, to receive deescalating doses of 17DD-YFV, from 27,476 IU to 31 IU. Blood samples were collected before vaccination (for neutralization tests to yellow fever, serology for dengue and clinical chemistry), 3 to $7 \mathrm{~d}$ after vaccination (for viremia and clinical chemistry) and $30 \mathrm{~d}$ after vaccination (for new yellow fever serology and clinical chemistry). Adverse events diaries were filled out by volunteers during $10 \mathrm{~d}$ after vaccination. Volunteers were retested for yellow fever and dengue antibodies 10 mo later. Seropositivity for dengue was found in $87.6 \%$ of volunteers before vaccination, but this had no significant influence on conclusions.

Conclusion: In young healthy adults Bio-Manguinhos/Fiocruz yellow fever vaccine can be used in much lower doses than usual.

International Register: ISRCTN 38082350.

\section{Introduction}

Two distinct strains of live attenuated yellow fever virus vaccine, $17 \mathrm{D}$ and $17 \mathrm{DD}$, have been used on a large scale. They have the same origin, from a yellow fever virus isolated from a patient with non fatal yellow fever named Asibi, from Ghana, in 1927. The $17 \mathrm{D}$ strain, used for vaccine production, corresponds to passage level $235-240$ and the 17DD to a passage level 286-287. ${ }^{1}$ The comparison of the nucleotide sequences of all $17 \mathrm{D}$ vaccines showed an overall homology of $99.2 \% .^{2}$

Due to expansion of yellow fever virus circulation in Latin America and Africa, several countries have included the yellow fever vaccine (YFV) on their regular immunizations programs, or conducted vaccination campaigns. However, the number of yellow fever vaccine producers has decreased during the past 20 y. There are 10 producers of yellow fever vaccines, but only 3 are prequalified by the World Health Organization and supply vaccines to international agencies: Bio-Manguinhos (Brazil), SanofiPasteur (France) and Institute Pasteur in Dakar (Senegal).

In 2008, the sudden increase on the demand for YFV forced Bio-Manguinhos to interrupt its exports to other countries. The Brazilian Ministry of Health requested Bio-Manguinhos for a dose-response study with the YFV, to verify its immunogenicity and safety in formulations with lower doses of the 17DD-YFV (Bio-Manguinhos is the only manufacturer using the 17DD substrain) in an effort for vaccine sparing. In addition the $\mathrm{MoH}$ 


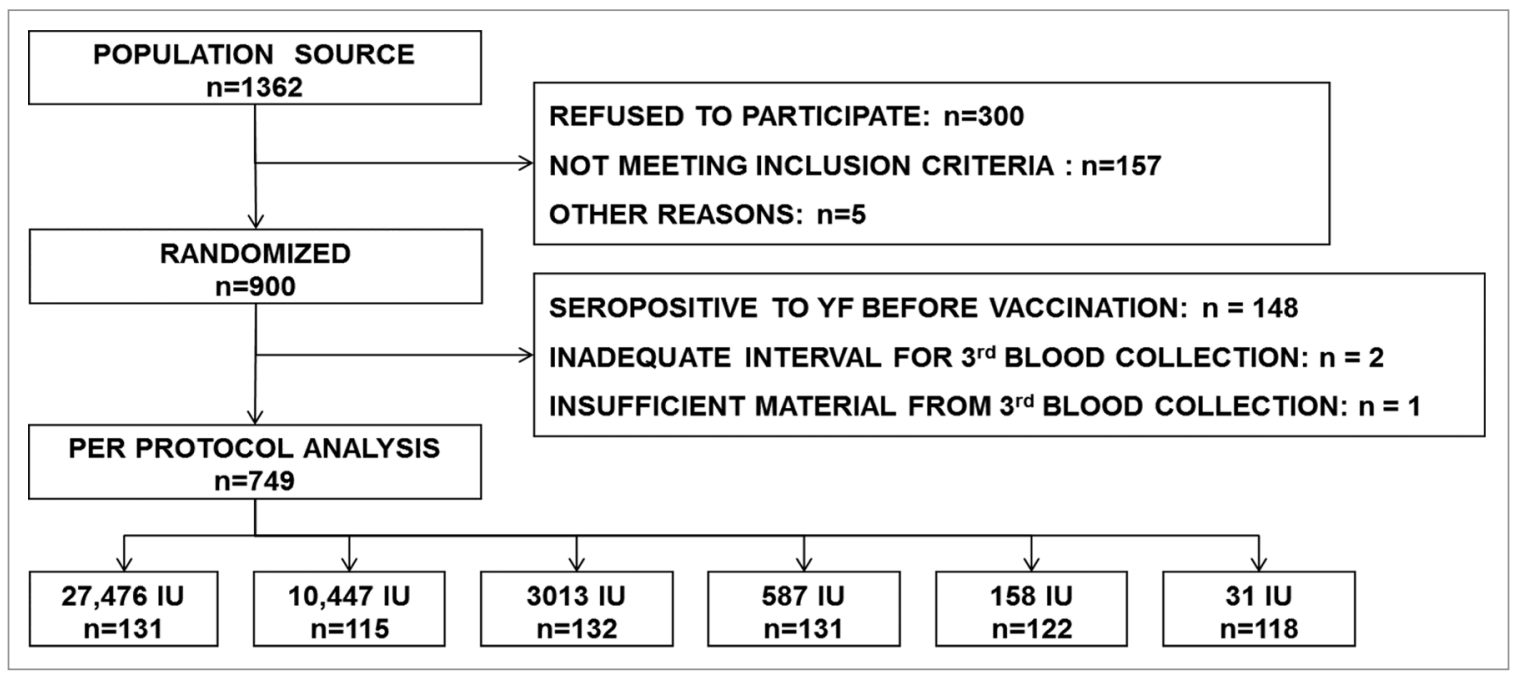

Figure 1. Study population.

Table 1. Baseline data

\begin{tabular}{cccc} 
Group IU/dose & $\begin{array}{c}\text { Age (years) } \\
\text { Mean }\end{array}$ & \% SP for dengue & $\begin{array}{c}\text { \% SP for } \\
\text { YF }\end{array}$ \\
\hline 27,476 IU & 19.1 & 91.9 & 12.7 \\
\hline 10,447 IU & 19.3 & 82.7 & 22.7 \\
\hline 3013 IU & 19.4 & 88.3 & 12.0 \\
\hline 587 IU & 19.5 & 85.3 & 12.7 \\
\hline 158 IU & 19.4 & 90.4 & 17.4 \\
\hline 31 IU & 19.2 & 86.2 & 21.2 \\
\hline
\end{tabular}

requested 5 million doses from the WHO strategic reserve. The need to increase Bio-Manguinhos production of YFV to meet this increase in demand from Brazil and other countries is clear.

The minimal number of viral particles in a vaccine dose has been established by WHO as at least $3 \log _{10} \mathrm{MLD}_{50}$ (mean lethal dose for $50 \%$ of a mice lot) or its corresponding dose in $\mathrm{PFU}^{3}$ and a maximum dose was not established. With methods used in BioManguinhos, the equivalent $3 \log 10$ MLD50 minimal dose of 17DD-YFV is $3.73 \log _{10}$ PFU, that is, approximately 5,000 PFU. Recently, a WHO working group recommended utilization of IU to define yellow fever vaccine dose. ${ }^{4}$

The number of viral particles in Bio-Manguinhos YFV, evaluated by the Quality Department in 2007, before the thermostability test, was on average 12 times (range 7 to 24 times) the minimum established by WHO. After undergoing the thermostability test, the number of viral particles was on average, 6.6 times the minimum required (range 2.3 to 12 times).

A vaccine with a lower number of viral particles, keeping its immunogenicity, could rapidly increase vaccine availability without placing a burden on the production units, and possibly respond the pressing needs from internal and external markets. Moreover, another possible gain would be less reactogenicity.

The objective of the current study was to investigate the immunogenicity and reactogenicity of $17 \mathrm{DD}-\mathrm{YFV}$, of vaccine formulations with lower number of viral particles than the standard vaccine.

As there was inconsistent information regarding the possible interference of dengue antibodies with the yellow fever vaccine immune response, we included serology for dengue to study possible interactions.

The study was approved by the Ethics Committee of Evandro Chagas Clinical Research Institute, from Fiocruz, and by the Brazilian Regulatory Agency-Anvisa, and was conducted according to good clinical practices. International Register: ISRCTN 38082350 .

\section{Results}

Nine hundred volunteers were recruited, with 150 volunteers per group (Fig. 1). Mean age was 19.4 y (SD: 1.2 y). The first and last blood samples were obtained from all volunteers, and the 2 nd blood sample from 872 volunteers. Blood samples were collected according to the prescribed intervals in $85.6 \%$ of volunteers for the $2^{\text {nd }}$ blood sample and in $99.6 \%$ of volunteers for the $3 \mathrm{rd}$ blood sample. There were no statistically significant differences among groups regarding these data.

Baseline data for age and serology for dengue showed a balanced distribution across vaccine groups, but the proportion seropositive for yellow fever differed substantially among groups ( $\mathrm{p}=$ 0.034, Pearson chi-square). Susceptibility to yellow fever before vaccination was found in $83.7 \%$ of volunteers born in Rio de Janeiro state (which made up $95.7 \%$ of the study group), and $75.9 \%$ in volunteers from other regions of the country where vaccination could have been recommended ( $p=0.304$, Fisher's exact test). Per protocol analysis for immunogenicity considered only volunteers susceptible to yellow fever before vaccination (Table 1).

Immunogenicity. Immunogenicity results are presented for the subset of volunteers susceptible to yellow fever before vaccination ( $\leq 2.7 \log 10 \mathrm{mIU} / \mathrm{mL}$, approximately $\leq 1: 20$ in dilution) and adherent to protocol $(n=749)$. Results for the whole cohort 
are similar, although immunogenicity was lower than among protocol adherers.

The proportion of seroconversion increased substantially with the viral concentration up to the formulation with 587 IU, and very little in formulations with higher concentrations (Table 2).

The lower $95 \%$ confidence limits for the difference in seroconversion between groups 10,447 IU, 3,013 IU, 587 IU and the reference group were $2.5 \%,-4.4 \%$, and $-5.5 \%$, respectively. For groups $158 \mathrm{IU}$ and $31 \mathrm{IU}$ these limits were $-16.2 \%$ and $-40.5 \%$, respectively.

GMTs increased substantially with vaccine dose up to 587 IU, and were similar among concentrations 587 IU or higher (Table 3).

Results on seroconversions considering different cut-offs, from $2.5 \mathrm{mIU} / \mathrm{mL}$ (approximately 1:10 in dilution) to 2.9 (approximately 1:30 in dilution) also showed that groups $158 \mathrm{IU}$ and 31 IU are clearly inferior to the others with the latter having similar immunogenicity.

Comparisons of seroconversions and GMTs including seropositives to yellow fever before vaccination also lead to the same conclusions, although confidence intervals are wider.

The reverse cumulative distribution of post-vaccination antibody titers showed similar immune responses for groups with $587 \mathrm{IU} /$ dose or more, and much lower for groups with $158 \mathrm{IU}$ and 31 IU/dose (Fig. 2). Differences were statistically significant for groups with $31 \mathrm{IU} /$ dose $(\mathrm{p}=0.000)$ and $158 \mathrm{IU} /$ dose ( $p=0.000)$, for comparisons with the reference vaccine.

Duration of immunity. The duration of immunity was studied in 839 volunteers approximately 10 mo after vaccination. The intervals between the initial vaccination and last blood sample were similar among groups, with medians from 287 to $292 \mathrm{~d}$. Evaluation of antibody persistence was analyzed in volunteers seronegative to yellow fever $\left(\leq 2.7 \log _{10} \mathrm{mIU} / \mathrm{mL}\right)$ before vaccination, who seroconverted and had not been revaccinated (Table 4). Differences among groups were statistically significant $(\mathrm{p}=0.001)$. When the $31 \mathrm{IU} /$ dose group was removed, differences were not statistically significant $(\mathrm{p}=0.4)$.

Reduction of GMTs occurred in all groups, with values approximately $1 / 3$ of initial titers (data not shown). GMTs of each group were not statistically different from the reference vaccine.

Reactogenicity. No serious adverse events attributable to the vaccine or experimental products were reported. Reactogenicity analyses included all volunteers who correctly filled out the Adverse Events Diaries (local pain, hyperemia, edema, headache, fatigue, arthralgia, pruritus, exanthema and nausea) during the first $10 \mathrm{~d}$ after vaccination, which was accomplished by $99 \%$ of volunteers. Headache and fatigue were the most frequent symptoms, being reported by more than $1 / 5$ of volunteers. The only statistically significant difference was pain, more frequent in the reference group $(27,476 \mathrm{IU} /$ dose $)-21.3 \%$ - than in groups $10,447 \mathrm{IU} /$ dose $(11.3 \% ; \mathrm{p}=0.028), 3,013 \mathrm{IU} /$ dose $(12.0 \%$; $\mathrm{p}=0.043) ; 587 \mathrm{IU} /$ dose $(13.3 \% ; \mathrm{p}=0.093), 158 \mathrm{IU} /$ dose $(10.1 \% ; \mathrm{p}=0.010)$ and $31 \mathrm{IU} /$ dose $(9.3 \% ; \mathrm{p}=0.004)$ (Fig. 3$)$.

Across vaccine groups, 121 to 130 volunteers correctly informed axillary temperatures during the first $10 \mathrm{~d}$ on diaries.
Table 2. Seroconversion rates according to virus concentration of vaccine against yellow fever

\begin{tabular}{cccccc}
$\begin{array}{c}\text { Group } \\
\text { IU/dose }\end{array}$ & No & Yes & Total & Proportion & $95 \% \mathrm{Cl}$ \\
\hline 27,476 IU & 3 & 128 & 131 & 0.977 & $0.935 ; 0.995$ \\
\hline 10,447 IU & 1 & 114 & 115 & 0.991 & $0.953 ; 1.000$ \\
\hline 3013 IU & 3 & 129 & 132 & 0.977 & $0.935 ; 0.995$ \\
\hline 587 IU & 4 & 127 & 131 & 0.969 & $0.924 ; 0.992$ \\
158 IU & 14 & 108 & 122 & 0.885 & $0.815 ; 0.936$ \\
31 IU & 39 & 79 & 118 & 0.669 & $0.577 ; 0.753$
\end{tabular}

'Seronegative before vaccination to seropositive or 4 -fold increase in titers $p=0.000$.

Overall, $15.2 \%$ had fever (axillary temperatures $\geq 37.5^{\circ} \mathrm{C}$ ) and $2 \%$ high fever (axillary temperatures $\geq 39^{\circ} \mathrm{C}$ ). Differences for fever or high fever among groups were not statistically significant.

There were no statistically significant differences among groups in the measurements of adverse events (hyperemia, edema and fever).

Abnormalities on biochemical tests were rare after the $2^{\text {nd }}$ or the $3^{\text {rd }}$ blood sample, scattered and had no group-related pattern.

Viremia. Viral plaquing. No viremia was detected by inoculation of Vero cells with volunteer serum samples collected after the 6 th day. Fourteen samples were collected on the $8^{\text {th }}$ day after vaccination, 10 on the thirteenth day, 11 on the fourteenth day, 10 on the fifteenth day and 12 on the sixteenth, and in lower numbers on the other days ( 0 viremias/100 blood samples, from 8 to $36 \mathrm{~d}$ after vaccination).

Among volunteers who were seropositive for YF before vaccination, the use of viral plaquing on Vero cell cultures allowed the detection of only one positive sample, from a volunteer belonging to the $27,476 \mathrm{IU} /$ dose group, with a titer of antibodies near the threshold for seropositivity $(2.73 \mathrm{mIU} / \mathrm{mL})$ and very low viremia level $(5.01 \mathrm{PFU} / \mathrm{mL})$ on the $6^{\text {th }}$ day after vaccination.

On the other hand, in volunteers who were seronegative for yellow fever before vaccination $(\leq 2.7 \log 10 \mathrm{mIU} / \mathrm{mL})$ vaccine virus was detected from 3 to $6 \mathrm{~d}$ after vaccination, mainly from 4 to $6 \mathrm{~d}$, within all groups. The proportion of positive samples (Table 5) and the levels of viremias (Table 6) did not appear to be related to the number of viral particles in the dose administered $(\mathrm{p}=0.29$ and $\mathrm{p}=0.73$, respectively).

There were only 4 volunteers with viremias $\geq 100 \mathrm{PFU} / \mathrm{mL}$, with values of $170 \mathrm{PFU} / \mathrm{mL}, 170 \mathrm{PFU} / \mathrm{mL}, 105 \mathrm{PFU} / \mathrm{mL}$ and $100 \mathrm{PFU} / \mathrm{mL}$, in groups with 3,013 IU, 10,447 IU, 10,447 IU and 587 IU, per dose, respectively.

GMT of neutralizing antibodies after vaccination of YF-naïve volunteers were apparently more elevated in volunteers positive for vaccine viral RNA $(11,835 \mathrm{mIU} / \mathrm{mL})$ than in volunteers for which no vaccine viral RNA could be detected $(8,058 \mathrm{mIU} / \mathrm{mL})$, but it lacked statistical significance $(\mathrm{p}=0.12)$.

There was no statistically significant difference in the frequency of pain, fever, high fever, or any other clinical symptom or laboratorial abnormality as far as viremia is concerned. 
Table 3. Geometric mean titers $(\mathrm{mlU} / \mathrm{mL})$ per group, and ratio of each group to the reference vaccine

\begin{tabular}{|c|c|c|c|c|}
\hline Group IU/dose & GMT (mIU/mL) & $95 \% \mathrm{Cl}(\mathrm{mlU} / \mathrm{mL})$ & GMT ratio to the reference group & $95 \% \mathrm{Cl}$ \\
\hline $27,476 \mathrm{IU}$ & $13,479.2$ & $11,078.9 ; 16,399.5$ & & \\
\hline 10,447 IU & $12,190.6$ & $10,153.3 ; 14,636.6$ & 0.904 & $0.691 ; 1.184$ \\
\hline $3013 \mathrm{IU}$ & $11,607.5$ & $9630.9 ; 13,989.8$ & 0.861 & $0.658 ; 1.127$ \\
\hline $587 \mathrm{IU}$ & $12,145.0$ & $9988.4 ; 14,767.3$ & 0.901 & $0.684 ; 1.187$ \\
\hline $158 \mathrm{IU}$ & 6837.3 & $5044.5 ; 9267.3$ & $0.507^{*}$ & $0.354 ; 0.727$ \\
\hline $31 \mathrm{IU}$ & 1970.2 & $1292.2 ; 3000.6$ & $0.146^{*}$ & $0.092 ; 0.232$ \\
\hline
\end{tabular}

${ }^{*} p=0.000$.

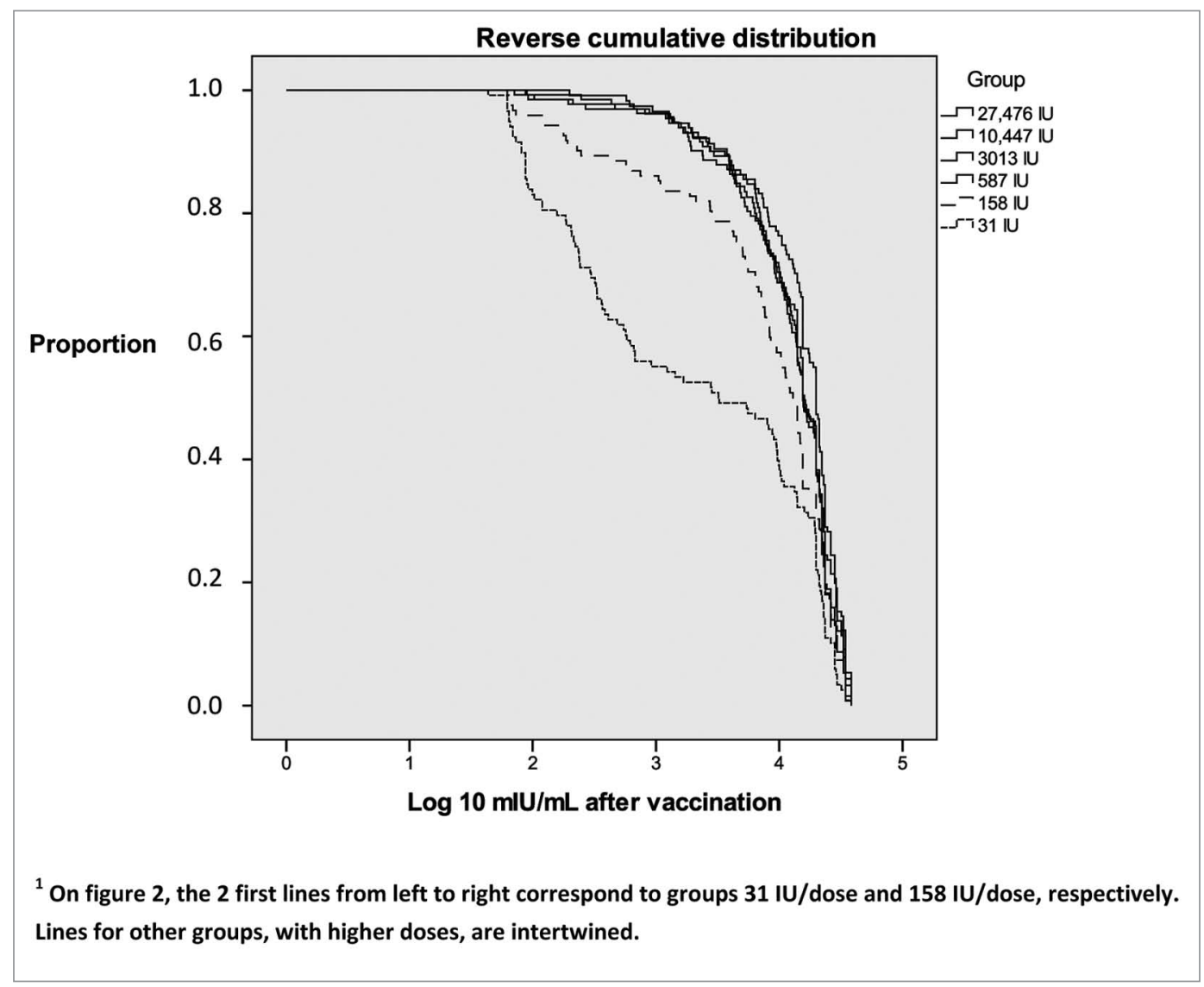

Figure 2. Reverse cumulative distribution of neutralizing antibodies titers per group. ${ }^{1}$

Table 4. Seroconversion in YF-naïve volunteers 10 mo after first vaccination

\begin{tabular}{|c|c|c|c|c|c|c|c|c|c|c|c|c|c|c|}
\hline \multirow[t]{2}{*}{ Group in IU/dose } & \multicolumn{2}{|c|}{ 27,476 IU } & \multicolumn{2}{|c|}{ 10,447 IU } & \multicolumn{2}{|c|}{3,013 IU } & \multicolumn{2}{|c|}{587 IU } & \multicolumn{2}{|c|}{$158 \mathrm{IU}$} & \multicolumn{2}{|c|}{$31 \mathrm{IU}$} & \multicolumn{2}{|c|}{ Total } \\
\hline & $\mathbf{n}$ & $\%$ & $\mathbf{n}$ & $\%$ & $\mathbf{n}$ & $\%$ & $\mathbf{n}$ & $\%$ & $\mathbf{n}$ & $\%$ & $\mathbf{n}$ & $\%$ & $\mathbf{n}$ & $\%$ \\
\hline Seronegative & 2 & 1.7 & 3 & 2.9 & 1 & 0.8 & 0 & 0 & 2 & 2 & 7 & 10.8 & 15 & 2.4 \\
\hline Seropositive & 115 & 98.3 & 102 & 97.1 & 117 & 99.2 & 116 & 100 & 98 & 98 & 58 & 89.2 & 606 & 97.6 \\
\hline Total & 117 & 100 & 105 & 100 & 118 & 100 & 116 & 100 & 100 & 100 & 65 & 100 & 621 & 100 \\
\hline
\end{tabular}

$R T-P C R$. The detection of viral RNA is considered to be more sensitive than plaquing human sera on cultured vertebrate cells. We used a real-time RT-PCR assay to re-examine the viremia in firsttime vaccinees. Altogether $38.4 \%$ of volunteers were found positive, but without statistically significant differences across groups. Overall, the frequency of viremias by virus plaquing and RT-PCR were poorly correlated, as frequencies were very different, but for the subgroup positive by plaquing correlation was high, 0.692 (Pearson). The pattern was similar regardless of seronegativity or seropositivity for dengue and/or yellow fever before vaccination.

There were higher counts of vaccine virus RNA copies on the first days after vaccination, but they were detected up to $36 \mathrm{~d}$ 
after vaccination (Fig. 4). The graph displays only values above the threshold for positivity. Accordingly, vaccine virus RNA positivity by RT-PCR was more frequent on the first $10 \mathrm{~d}$ after vaccination (Table 7).

GMT of neutralizing antibodies after vaccination of YF-naïve volunteers were more elevated for those who displayed viral RNA copies-10,669 $\mathrm{mIU} / \mathrm{mL}$ than in samples from volunteers negative by RT-PCR - 6,915 mIU/mL, p $=0.000$. RT-PCR positivity was more frequent on volunteers with local pain $(p=0.024)$, but for other adverse events there was no statistically significant association.

Serology for dengue interactions. Serology for dengue before vaccination was done in $91.2 \%$ of volunteers. Among YF naïve volunteers, previous seropositivity to dengue led to decreased YF GMTs 1 mo after vaccination, with marginal statistical significance $(\mathrm{p}=0.056)$. Groups which received $31 \mathrm{IU}$ and $158 \mathrm{IU}$ doses remained with immunogenicity inferior to the other groups after adjusting to dengue and yellow fever susceptibility before vaccination, on logistic regression for seroconversion and linear regression for yellow fever antibody titers. Serology for dengue on the $4^{\text {th }}$ blood sample, approximately 10 mo after vaccination, was done in $91.6 \%$ of volunteers. On paired analysis, seropositivity for dengue was $87.7 \%$ before vaccination and $90.6 \%$ at the 4 th blood sample. During the study $3.3 \%$ of volunteers seroconverted to dengue and $0.4 \%$ became seronegative. Among YF naïve volunteers, seropositivity to dengue had no statistically significant influence on seropositivity or GMTs for YF at $10 \mathrm{mo}$ after vaccination.

Viremias measured by viral plaquing were more frequent among volunteers seronegative to dengue and yellow fever before vaccination (Table 8).

Mean viremias were $1.71 \mathrm{PFU} / \mathrm{mL}$ for volunteers seronegative to dengue before vaccination and $1.03 \mathrm{PFU} / \mathrm{mL}$ for seropositive ( $\mathrm{p}=0.000)$, suggesting the influence of anti-dengue antibodies in YF 17DD virus viremia, as measured by viral plaquing. Results are similar when we consider only YF-naive volunteers with $<2.6 \log _{10} \mathrm{mIU} / \mathrm{mL}$ before vaccination.

Vaccine virus positivity by RT-PCR was similar in dengueseropositive and dengue-seronegative individuals, and the mean of vaccine virus RNA copies was higher in individuals seronegative to dengue before vaccination, but without statistical significance.

\section{Discussion}

Previous yellow fever vaccine dose-response studies included a relatively small number of volunteers per vaccine group and employed methods different from those in current use, making comparisons and recommendations for a minimal effective dose difficult. ${ }^{5-9}$ The relationship among mouse lethal dose (MLD50), plaque forming units (PFU) and international units
(IU) is variable. However, World Health Organization requires that yellow fever vaccine dose must have at least $1,000 \mathrm{MLD}_{50}$ or its equivalent in PFU. ${ }^{3} \mathrm{~A}$ WHO working group recommended in 2008 the use of international units for defining vaccine dose. ${ }^{4}$ There are no recommendations for maximum dose.

Lopes et al. (1988) evaluated the immune response to 17DD yellow fever vaccine in a dose-response study, ${ }^{7}$ in 259 military volunteers from 18 to $47 \mathrm{y}$ of age (mean $21.6 \mathrm{y}$ ). Doses from < $20 \mathrm{PFU}$ to $2000 \mathrm{PFU}$ were administered. With > $200 \mathrm{PFU} /$ dose (about 69 LD50, by the methodology in use at that time) seroconversion was $100 \%$, and with 100 to $200 \mathrm{PFU}$ seroconversion was $93.7 \%$. With lower doses seroconversion rates were lower and GMTs did not appear to be related to dose among seroconverters. Titers in PFU were calculated with methods different from those currently used, thus limiting comparisons.

In the current study, for volunteers without previous immunity for YF, the lowest dose groups, with 31 IU and 158 IU, were those with lowest seroconversion rates and GMTs. However, it is remarkable that the group with $31 \mathrm{IU}$ had $67 \%$ seroconversion, and the 158 IU group had 89\% seroconversion, demonstrating the high immunogenicity of the $17 \mathrm{DD}$ yellow fever vaccine. The other groups displayed seroconversion rates around $98 \%$, and with no statistically significant differences among them, when seroconversion rates or GMTs were compared.

Significant levels of neutralizing antibodies and the overall rate of positivity were maintained satisfactorily during $10 \mathrm{mo}$ on almost all volunteers, except on the lowest dose group (31 IU), although $89.2 \%$ remained positive. This is compatible with studies of duration of immunity with YF vaccine. ${ }^{10-13}$ However, that does not imply seropositivity will be maintained equally for all groups above $31 \mathrm{IU}$ during the following years.

Excluding the studies done recently at Bio-Manguinhos by Camacho et al. and Santos et al., ${ }^{14,15}$ the number of volunteers on clinical studies evaluating viremia by virus isolation has been small, even fewer were studied by RT-PCR and restricted to the first days after vaccination. ${ }^{16-24}$ Different laboratory methods 
Table 5. Viral detection by day of blood sample and group: number of isolations/number of blood samples (\% isolations)

\begin{tabular}{|c|c|c|c|c|c|c|}
\hline \multirow{2}{*}{ GrouplU/dose } & \multicolumn{5}{|c|}{ Day of blood sample after vaccination } & \multirow{2}{*}{ Total } \\
\hline & 3 & 4 & 5 & 6 & 7 & \\
\hline 27,476 & $0 / 20(0)$ & $1 / 19(5.3)$ & $0 / 26(0)$ & $0 / 27(0)$ & $0 / 13(0)$ & $1 / 105(1)$ \\
\hline 10,447 & $0 / 17(0)$ & $2 / 14(14.3)$ & 4/27 (14.8) & $1 / 29(3.4)$ & $0 / 15(0)$ & $7 / 102(6.9)$ \\
\hline 3013 & $1 / 22(4.5)$ & $1 / 14(7.1)$ & $2 / 30(6.7)$ & $1 / 24(4.2)$ & $0 / 13(0)$ & $5 / 103(4.9)$ \\
\hline 587 & $0 / 17(0)$ & $1 / 20(5)$ & $4 / 26(15.4)$ & $1 / 29(3.4)$ & $0 / 13(0)$ & $6 / 105(5.7)$ \\
\hline 158 & $0 / 22(0)$ & $0 / 17(0)$ & $2 / 21(9.5)$ & $1 / 32(3.1)$ & $0 / 10(0)$ & $3 / 102(2.9)$ \\
\hline 31 & $0 / 13(0)$ & $0 / 25(0)$ & $2 / 24(8.3)$ & $3 / 30(10)$ & $0 / 11(0)$ & $5 / 103(4.9)$ \\
\hline Total & $1 / 111(0.9)$ & $5 / 109$ (4.6) & 14/154 (9.1) & $7 / 171(4.1)$ & $0 / 75(0)$ & $27 / 620(4.4)$ \\
\hline
\end{tabular}

Table 6. Levels of viremia by group

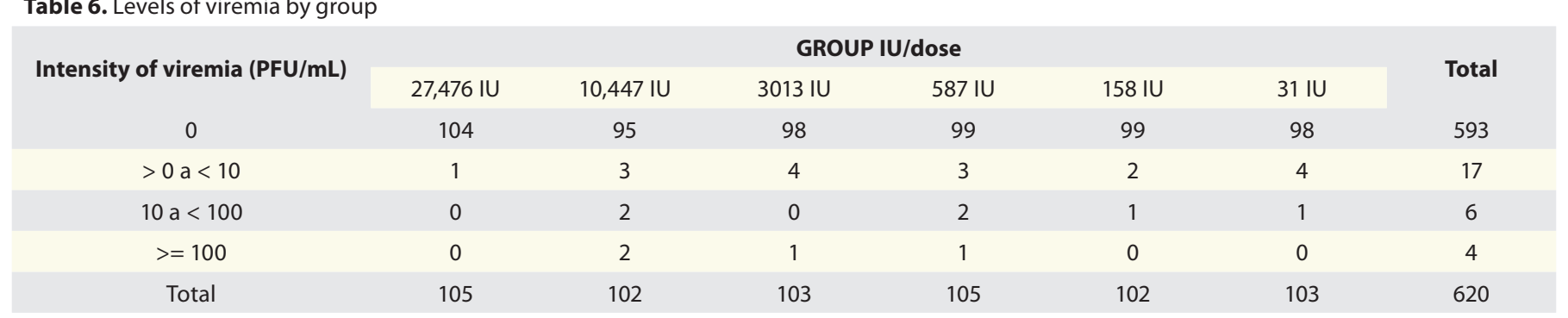

were used, and in general there were several blood samples per volunteer. Frequencies of virus detection by isolation were high, from $45 \%$ to $100 \%$, and slightly higher and longer by RT-PCR. In all cases viremia was transient and of low intensity.

In contrast, on the recent studies at Bio-Manguinhos, a very low frequency of viremia was found, $2.7 \%$ in 815 adults, with a single blood sample from each subject, collected 3 to $7 \mathrm{~d}$ after vaccination. On Santos et al. study there were no viremias by plaquing or RT-PCR in 8 naïve adults, with 3 blood samples for each individual.

In the current study, vaccine virus RNA copies were identified in serum until $36 \mathrm{~d}$ after vaccination, although more frequently and with higher intensity in the first $10 \mathrm{~d}$. Recent papers reported frequent $(44 \%)$ or prolonged (until $198 \mathrm{~d}$ ) shedding of vaccine RNA in urine of vaccinated individuals. ${ }^{25,26}$ This should alert against considering RT-PCR positivity on serum after $10 \mathrm{~d}$ as an indication of yellow fever vaccine-associated viscerotropic disease, as has been proposed recently. ${ }^{27}$

Data from the current study indicate that seropositivity for dengue before vaccination contributed to decrease the frequency of viremia of YF 17DD virus. It is highly unlikely that such a strong association be explained by unreported previous vaccination against yellow fever inducing cross-reactivity to dengue. In this study, 10 mo after yellow fever vaccination, only a small number of volunteers had seroconverted to dengue, most probably due to the disease itself. Moreover, differences in viremia was assessed only among yellow fever naïve volunteers and the difference was maintained even when the cut-off for yellow fever seropositivity was set at $2.6 \log _{10} \mathrm{PFU} / \mathrm{mL}$, lower than the current standard of $2.7 \log _{10} \mathrm{PFU} / \mathrm{mL}$. Interestingly, an association between dengue antibodies and protection against severe yellow fever disease has been recently reported. ${ }^{28}$ This finding could explain the low frequency of viremia found recently in studies done in Brazil, where dengue epidemics by several serotypes have occurred during the last decades.

Based on Table 1, all groups showed seropositivity to dengue of 82.7 to $91.9 \%$. Since data suggests a reduction in vaccine virus viremia due to cross-neutralization with anti-dengue antibody, a reduction in anti-YF neutralizing antibody titers (both magnitude and proportion) would also be expected (Tables 2 and 3 ). However, this is not observed in groups that received doses as low as $587 \mathrm{IU}$ of $17 \mathrm{DD}$ virus, which induced an immune response to YF similar to the highest dose group (Table 2). This observation reinforces the $587 \mathrm{IU}$ of virus as the minimal dose for successful immunization against YF, even in the presence of measurable titers of anti-dengue antibodies, an extremely important observation given the endemic profile of dengue in Brazil.

Reactogenicity was low for all groups. Only pain was more frequent in the reference group, with the largest dose (27,476 IU). The current study has not enough power to define if lower yellow fever vaccine doses may be followed by a decrease in serious adverse events, such as vaccine-associated viscerotropic disease. On the other hand, information about the effect of large doses administered inadvertently is scant, based in few individuals and does not permit conclusions. ${ }^{29,30}$

These results should be verified in individuals with other demographic characteristics, such as age. In recent studies lower immunogenicity was observed in children less than 12 mo of age vaccinated with yellow fever vaccines substrains $17 \mathrm{DD}$ and 17D213 , as compared with adults studied by the same group with the same vaccines. ${ }^{14,31}$ Lower immunogenicity in children than in adults was also observed in a study done in Peru with $17 \mathrm{D}$ yellow fever vaccine..$^{32}$ 


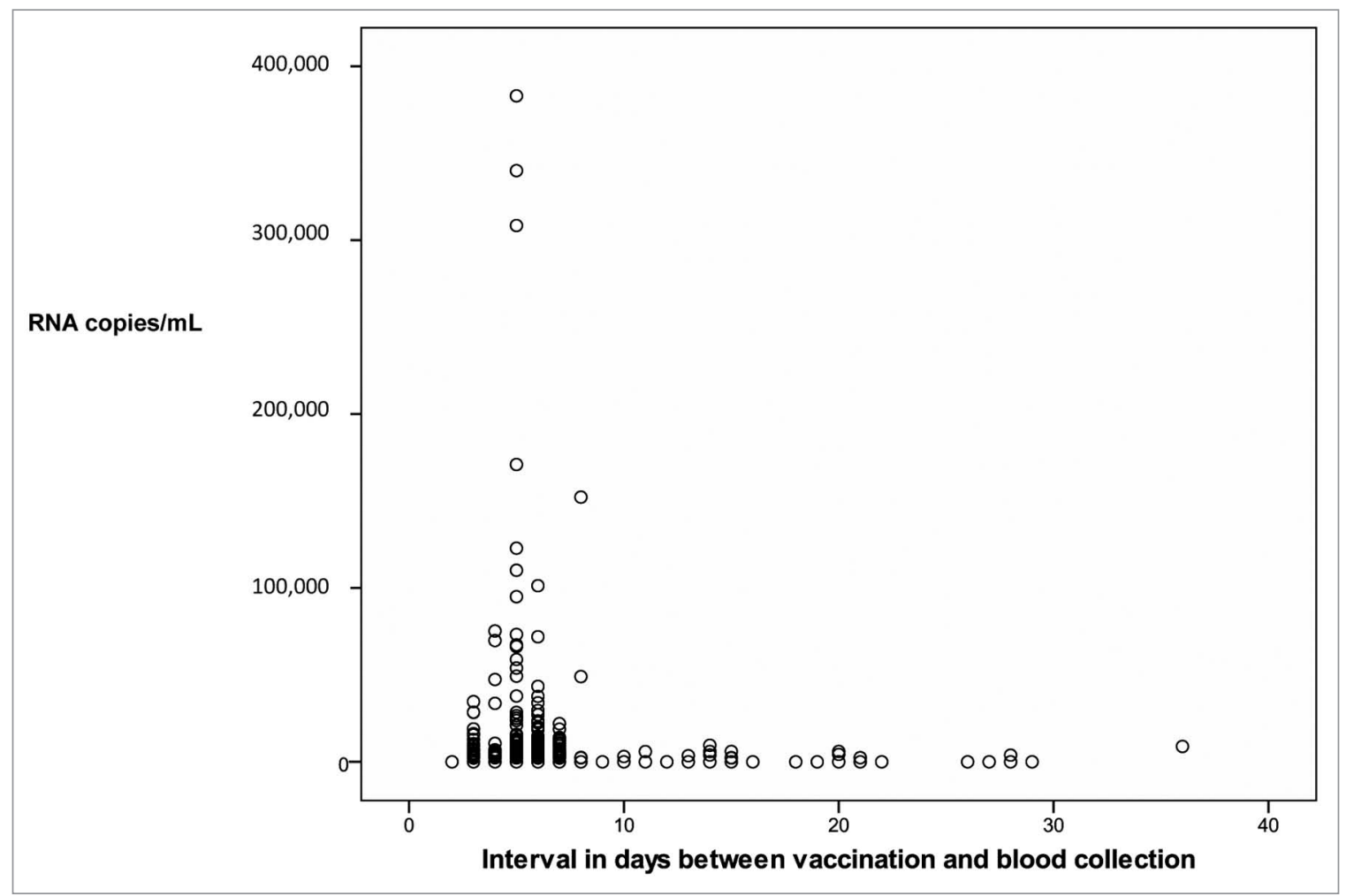

Figure 4. Number of viral RNA copies by day after vaccination.

\section{Materials and Methods}

Study design. This is a non-inferiority study to compare each of 5 alternative formulations for yellow fever vaccine, with lower concentrations of viral particles, to the vaccine in routine use by the National Immunizations Program. Volunteers were randomized to 6 groups assigned to vaccine formulations of decreasing amounts of viral particles. The highest dose was the current commercial vaccine taken as the reference group.

All procedures were taken for blinding the doses corresponding to the groups from interviewers, researchers and laboratory personnel, until conclusion of data analysis. Vaccine vials were masked and labeled at Bio-Manguinhos, under supervision of representatives from the Brazilian National School of Public Health, of Bio-Manguinhos Quality Department and a statistician, without any participation of researchers involved in field work or laboratory tests.

Blood was collected before vaccination for neutralizing antibodies to yellow fever, dengue IgG and for clinical chemistry tests, at $5 \mathrm{~d}$ ( 3 to $7 \mathrm{~d}$ were accepted) after vaccination, for clinical chemistry and viremia and $30 \mathrm{~d}$ (accepted range 21 to $100 \mathrm{~d}$ ) after vaccination, for clinical chemistry and YF neutralizing antibodies measurements.

At the end of the study, those volunteers, which did not show seroconversion to yellow fever were revaccinated with the reference vaccine.

Approximately 10 mo after vaccination (with acceptance from 9 to $15 \mathrm{mo}$ ) a blood sample was collected for serologic tests for
Table 7. Vaccine virus RNA positivity by RT-PCR at specific intervals between vaccination and blood sampling

\begin{tabular}{|cccc|}
\hline & $<\mathbf{1 1} \mathbf{d}$ & $\mathbf{1 1 1} \mathbf{d}$ to $<\mathbf{1 4} \mathbf{d}$ & $\geq \mathbf{1 4} \mathbf{d}$ \\
\hline N & 787 & 19 & 65 \\
\hline \% RT-PCR positive & $42.3 \%$ & $10.5 \%$ & $16.9 \%$ \\
\hline
\end{tabular}

Table 8. Virus detection and dengue serology before vaccination, only volunteers susceptible to yellow fever before vaccination and with adequate blood sampling interval for viremia

\begin{tabular}{|ccccc|} 
Virus plaquing & \multicolumn{4}{c}{ Serology for dengue } \\
& \multicolumn{2}{c}{ Negative } & \multicolumn{2}{c|}{ Positive } \\
\hline Negative & N & $\%$ & N & $\%$ \\
\hline Positive & 66 & 81.5 & 474 & 97.9 \\
\hline Total & 15 & 18.5 & 10 & 2.1 \\
\hline$p=0.000$ (Fisher). & 81 & 100 & 484 & 100 \\
\hline
\end{tabular}

yellow fever and dengue. This was not a criterion for protocol adherence. Volunteers seronegative $(\leq 2.7 \log 10 \mathrm{mIU} / \mathrm{mL}$ on neutralization test) at this time were revaccinated with the reference vaccine.

Adherence to protocol regarding immunogenicity was met if volunteer had blood samples before vaccination and 30 (21$100 \mathrm{~d})$ days after.

The occurrence of adverse events was evaluated among volunteers who recorded them on their diaries at all times as requested. 
Population and study groups. Study subjects were healthy, male, young adults, army conscripts from Rio de Janeiro (a yellow fever non-endemic area) who: (1) informed that they had no previous vaccination against yellow fever; (2) had no personal history of diseases which could increase the risk for untoward effects of yellow fever vaccination; and (3) agreed with and signed a consent form.

Vaccines. The experimental products had the viral particle concentrations in International Units (1 IU corresponded to 1.91 PFU on this study) per dose, measured according to an international standard from National Institute for Biological Standards and Control, Potters Bar, England. The following titers were obtained, per human dose, for each arm: (1) vaccine in current use (reference), 27,476 IU or 52,480 PFU; (2) 10,447 IU or 19,953 PFU; (3) 3,013 IU or 5,754 PFU; (4) 587 IU or 1,122 PFU; (5) 158 IU or 302 PFU; (6) 31 IU or 59 PFU.

The composition of experimental vaccines was identical to the reference vaccine, except for lower concentration of viral particles and egg proteins. Vaccines were stored from $2^{\circ} \mathrm{C}$ to $8^{\circ} \mathrm{C}$ for 24 mo, without reduction of viral titers.

Reactogenicity and immunogenicity evaluation. Volunteers filled out a Diary for Adverse Events during the first $10 \mathrm{~d}$ after vaccination, and were asked to report all adverse events for the study duration. Intensity of adverse events was evaluated in a scale from 0 to 4, according to the Food and Drug Administration guidelines. ${ }^{33}$

Clinical chemical tests were done before and after vaccination and viremia by sera plaquing on the first days after vaccination. Clinical chemistry tests targeted renal (creatinine), hepatic (aspartate amino-transferase and alanine amino-transferase) and pancreatic functions (amylase and lipase). Viral titration was performed in Vero cells monolayers, as described by Caufour. ${ }^{34}$ Sixwell plates were used, with Vero cells seeded $24 \mathrm{~h}$ before the test.

Viral RNA copy numbers were established by RT-PCR. The standard curve was established using in vitro transcribed RNA with part of YF NS5 genome region cloned in a plasmid. The RNA was serially diluted from $10^{7}$ to $10^{2}$ copies. The standard curve to TaqMan assay was standardized and validated and shown to be linear, specific, sensitive and reproducible, meeting the pre requirements to issue a reliable result and to be used as a reference to quantify unknown samples. A serum sample was considered positive when titers were $\geq 2147$ RNA copies $/ \mathrm{mL}$. To determine the limit of quantification (LOD), serial dilutions of yellow fever virus ( $10^{7}$ to 6.25 RNA copies/reaction) were made and eight independent replicates were analyzed in the same assay. The lowest concentration that allowed $50 \%$ of detectable replicates, was considered the LOD, in this case the dilution of virus with 25 copies/reaction or 2147 copies $/ \mathrm{mL}$.

The titration of antibodies against yellow fever was performed at Virologic Technology Laboratory of Bio-Manguinhos (LATEV, Fiocruz) with Plaque Reduction Neutralization Test (PRNT). This test was conducted in serial 2-fold dilutions starting at 1:5, in volumes of $50 \mu \mathrm{l}$ of inactivated serum samples in 96 well tissue culture plates. Twenty five plaque-forming units (pfu) of yellow fever virus (strain 17D 213/77, lot UEXVFB01, Dec 1011) in $50 \mu \mathrm{l}$ are dispensed into all wells. A positive serum sample with yellow fever antibody content calibrated by a WHO International Reference Preparation is included in each set of test. ${ }^{35}$ The $\log _{10}$ dilution of the test and standard serum, which reduces the plaque numbers by $50 \%$ relative to the virus control, is determined by linear regression. The mean antibody titer at the $50 \%$ end point of the standard serum is then calculated and added to the $\log _{10}$ end point for each sample to give $\log _{10} \mathrm{mIU} /$ $\mathrm{ml}$. Results are given in absolute or $\log 10$ reciprocal of dilution or $\mathrm{mUI} / \mathrm{mL}$. We chose $\mathrm{mIU} / \mathrm{mL}$ to improve comparability of results. The $2.7 \mathrm{mIU} / \mathrm{mL}$ cut-off was used before in a previous published study by our group ${ }^{31}$ and it corresponds to a titer of approximately $1: 20$ in dilution.

Tests for yellow fever were done blindly at the BioManguinhos Viral Technology Laboratory, with recodification of samples, to avoid identification of any sample. IgG serology for dengue (ELISA) was done at Oswaldo Cruz Institute Flavivirus Laboratory.

Statistical considerations. An alternative vaccine formulation would be considered non-inferior if the lower limit of the $95 \%$ confidence interval of the difference in seroconversion rates did not exceed 5 percentage points. Additionally, the lower limit of the $95 \%$ confidence interval of the ratio of neutralizing antibody GMT in each alternative formulation and the GMT in the reference vaccine should be 0.5 or higher.

The estimated 130 volunteers for each group were raised to 150 to compensate for possible losses. With 130 volunteers per group it would be possible to detect 9 percentage points on the proportion of adverse events on the different formulations. As seropositivity for yellow fever before vaccination influences considerably the immunological response to vaccination, only volunteers seronegative for yellow fever before vaccination were included in the primary analysis of immunogenicity.

Subjects seronegative to yellow fever before vaccination who became seropositive after vaccination, or a 4-fold increase in neutralizing antibodies compared with prevaccination, were considered as adequately responding to vaccination (seroconverters). Results of each group were compared with the reference vaccine and $95 \%$ confidence intervals of the differences in proportions between each group and the reference vaccine were calculated.

GMTs were calculated after logarithmic transformation and the ratio of GMT in each group to the reference vaccine was also estimated with 95\% confidence intervals. Cumulative reverse distributions of antibody titers were constructed and Breslow test was used for comparison of each group to the reference vaccine.

The proportion of viremias detected for each group was compared with the reference vaccine. Clinical reactogenicity was assessed by the proportion of subjects with solicited signs or symptoms during the first $10 \mathrm{~d}$ after vaccination, and the proportion with any signs or symptoms for the whole period of study. Proportions of adverse events were tabulated by group and compared among them and with the reference group using chisquare and Fisher's test as indicated. Biochemical test results were dichotomized in normal or abnormal and analyzed by similar methodology. Logistic and linear regressions, when done, are indicated on text. For statistical analyses significance level was $5 \%$ and $95 \%$ confidence intervals were calculated. SPSS v. 16, 
NCSS v. $07 \cdot 1 \cdot 20,{ }^{36}$ WINPEPI v. $11.4^{37}$ and Open Epi, v. $2.2^{38}$ were used.

\section{Conclusions}

Results on this study indicate that immunogenicity of vaccine formulations with $587 \mathrm{IU}$ or more per dose is similar to the $27,476 \mathrm{IU}$ dose in current use in the short and mid-term. There were no differences among groups regarding common adverse events, with exception of pain, found more frequently with the larger dose, reference vaccine. There were no differences across groups regarding proportion or intensity of viremias detected by viral plaquing or RT-PCR. Considering also the excellent data for vaccine stability observed during the study, it does not seem justifiable to keep the high dose in current use as a standard. However, changes in vaccine formulation will require that these results be confirmed in infants, who are the target population for vaccination in endemic areas. In addition, long-term neutralizing antibody titers to YF should be followed up for longer periods.

\section{Disclosure of Potential Conflicts of Interest}

Reinaldo M. Martins, Maria de Lourdes S. Maia, Roberto Henrique G. Farias, Vera Maria M. Benjamin, Marcos S. Freire, Ricardo Galler, Anna Maya Yoshida, Luiz Fernando C.

\section{References}

1. Marchevsky RS, da Luz Leal M, Homma A, Coutinho ESF, Camacho LAB, Jabor AV, et al. Molecular and phenotypic analysis of a working seed lot of yellow fever virus $17 \mathrm{DD}$ vaccine strain produced from the secondary seed lot $102 / 84$ with an additional passage in chicken embryos. Biologicals 2006; 34:191-7; PMID:16326110; http://dx.doi.org/10.1016/j.biologicals.2005.09.005.

2. Stock NK, Boschetti N, Herzog C, Appelhans MS, Niedrig M. The phylogeny of yellow fever virus 17D vaccines. Vaccine 2012; 30:989-94; PMID:22197965; http://dx.doi.org/10.1016/j.vaccine.2011.12.057.

3. World Health Organization. Who Technical Report Series 872, Annex 2, Requirements for yellow fever vaccine, 1998 .

4. World Health Organization. Expert Committee on Biological Standardization. Requirements for yellow fever vaccine (Requirements for Biological Substances $\left.\mathrm{n}^{\circ} 3\right)$. WHO, 2008

5. Fox JP, Kossobudzki SL, Cunha JF. Field studies of the immune response to $17 \mathrm{D}$ yellow fever virus. Am J Hyg 1943; 38:113-38.

6. Smith CE, Turner LH, Armitage P. Yellow fever vaccination in Malaya by subcutaneous injection and multiple puncture. Neutralizing antibody responses in persons with and without pre-existing antibody to related viruses. Bull World Health Organ 1962; 27:717-27; PMID:13993152.

7. Lopes O de S, Guimarães SSDA, de Carvalho R. Studies on yellow fever vaccine. III--Dose response in volunteers. J Biol Stand 1988; 16:77-82; PMID:3372545; http://dx.doi.org/10.1016/0092-1157(88)90034-0.

8. Freestone DS, Ferris RD, Weinberg AL, Kelly A. Stabilized 17D strain yellow fever vaccine: dose response studies, clinical reactions and effects on hepatic function. J Biol Stand 1977; 5:181-6; PMID:893464; http://dx.doi.org/10.1016/S0092-1157(77)80003-6.

9. Monath TP, Cetron MS, Teuwen DE. Yellow fever vaccines. In: Plotkin S, Orenstein W, Offit P. Vaccines, 5th ed, Saunders Elsevier, China, 2008, p. 959-1055.
10. Niedrig M, Lademann M, Emmerich P, Lafrenz M. Assessment of IgG antibodies against yellow fever virus after vaccination with $17 \mathrm{D}$ by different assays: neutralization test, haemagglutination inhibition test, immunofluorescence assay and ELISA. Trop Med Int Health 1999; 4:867-71; PMID:10632996; http:// dx.doi.org/10.1046/j.1365-3156.1999.00496.x.

11. Poland JD, Calisher CH, Monath TP, Downs WG, Murphy K. Persistence of neutralizing antibody 30-35 years after immunization with $17 \mathrm{D}$ yellow fever vaccine. Bull World Health Organ 1981; 59:895-900; PMID:6978196.

12. Groot H, Ribeiro RB. Neutralizing and haemagglutination-inhibiting antibodies to yellow fever 17 years after vaccination with $17 \mathrm{D}$ vaccine. Bull World Health Organ 1962; 27:699-707; PMID:13950710.

13. de Melo $\mathrm{AB}$, da Silva $\mathrm{M}$ da $\mathrm{P}$, Magalhães $\mathrm{MCF}$, Gonzales Gil LH, Freese de Carvalho EM, Braga-Neto UM, et al. Description of a prospective 17DD yellow fever vaccine cohort in Recife, Brazil. Am J Trop Med Hyg 2011; 85:739-47; PMID:21976581; http:// dx.doi.org/10.4269/ajtmh.2011.10-0496.

14. Camacho LAB, Freire M da S, Leal M da L, Aguiar SG, Nascimento JP, Iguchi T, et al.; Collaborative Group for the Study of Yellow Fever Vaccines. Immunogenicity of WHO-17D and Brazilian 17DD yellow fever vaccines: a randomized trial. Rev Saude Publica 2004; 38:671-8; PMID:15499438; http://dx.doi.org/10.1590/S003489102004000500009 .

15. Santos AP, Bertho AL, Dias DC, Santos JR, Marcovistz R. Lymphocyte subset analyses in healthy adults vaccinated with yellow fever 17DD virus. Mem Inst Oswaldo Cruz 2005; 100:331-7; PMID:16113878; http:// dx.doi.org/10.1590/S0074-02762005000300021.

16. Smith HH, Penna HA, Paoliello A. Yellow fever vaccination with cultured virus (17D) without immune serum. Am J Trop Med 1938; 18:437-68.

17. Sweet BH, Wisseman CL Jr., Kitaoka M, Tamiya T. Immunological Studies with group B arthropod-borne viruses. II. Effect of prior infection with Japanese encephalitis virus on the viremia in human subjects following administration of $17 \mathrm{D}$ yellow fever vaccine. Am J Trop Med Hyg 1962; 11:562-9.
18. Wheelock EF, Sibley WA. Circulating virus, interferon and antibody after vaccination with the 17-D strain of yellow-fever virus. N Engl J Med 1965; 273:1948; PMID:14306335; http://dx.doi.org/10.1056/ NEJM196507222730404.

19. Santiago Actis A, Sa Fleitas MJ. Relaciones entre viremia y sero-anticuerpos secundarios a la vacunación antiamarílica de personas vacundas con "cepa 17D-EP. Rev Sanid Milit Argent 1970; 69:51-63; PMID:5530987.

20. Monath TP, McCarthy K, Bedford P, Johnson CT, Nichols R, Yoksan S, et al. Clinical proof of principle for ChimeriVax: recombinant live, attenuated vaccines against flavivirus infections. Vaccine 2002; 20:1004-18; PMID:11803060; http://dx.doi.org/10.1016/S0264410X(01)00457-1.

21. Monath TP, Guirakhoo F, Nichols R, Yoksan S, Schrader R, Murphy C, et al. Chimeric live, attenuated vaccine against Japanese encephalitis (ChimeriVax-JE): phase 2 clinical trials for safety and immunogenicity, effect of vaccine dose and schedule, and memory response to challenge with inactivated Japanese encephalitis antigen. J Infect Dis 2003; 188:1213-30; PMID:14551893; http://dx.doi.org/10.1086/378356.

22. Reinhardt B, Jaspert R, Niedrig M, Kostner C, LageStehr J. Development of viremia and humoral and cellular parameters of immune activation after vaccination with yellow fever virus strain 17D: a model of human flavivirus infection. J Med Virol 1998; 56:15967; PMID:9746073; http://dx.doi.org/10.1002/ (SICI) 1096-9071(199810)56:2<159::AID-JMV10> 3.0.CO;2-B.

23. Roukens AH, Vossen AC, Bredenbeek PJ, van Disse JT, Visser LG. Intradermally administered yellow fever vaccine at reduced dose induces a protective immune response: a randomized controlled non-inferiority trial. PLoS ONE 2008; 3:e1993; PMID:18431480; http:// dx.doi.org/10.1371/journal.pone.0001993. 
24. Roukens AH, Soonawala D, Joosten SA, de Visser AW, Jiang X, Dirksen K, et al. Elderly subjects have a delayed antibody response and prolonged viraemia following yellow fever vaccination: a prospective controlled cohort study. PLoS ONE 2011; 6:e27753; PMID:22163273; http://dx.doi.org/10.1371/journal. pone. 0027753 .

25. Domingo C, Yactayo S, Agbenu E, Demanou M, Schulz AR, Daskalow K, et al. Detection of yellow fever 17D genome in urine. J Clin Microbiol 2011; 49:7602; PMID:21106799; http://dx.doi.org/10.1128/ JCM.01775-10.

26. Martínez MJ, Vilella A, Pumarola T, Roldan M, Sequera VG, Vera I, et al. Persistence of yellow fever vaccine RNA in urine. Vaccine 2011; 29:3374-6; PMID:21385635; http://dx.doi.org/10.1016/j.vaccine.2011.02.075.

27. Gershman MD, Staples JE, Bentsi-Enchill AD, Breugelmans JG, Brito GS, Camacho LAB, et al.; Brighton Collaboration Viscerotropic Disease Working Group. Viscerotropic disease: case definition and guidelines for collection, analysis, and presentation of immunization safety data. Vaccine 2012; 30:5038-58; PMID:22561144; http://dx.doi.org/10.1016/j.vaccine.2012.04.067.

28. Izurieta RO, Macaluso M, Watts DM, Tesh RB, Guerra B, Cruz LM, et al. Anamnestic immune response to dengue and decreased severity of yellow Fever. J Glob Infect Dis 2009; 1:111-6; PMID:20300401; http:// dx.doi.org/10.4103/0974-777X.56257.
29. Rabello A, Orsini M, Disch J, Marcial T, Leal M da L, Freire $\mathrm{M}$ da $\mathrm{S}$, et al. Low frequency of side effects following an incidental 25 times concentrated dose of yellow fever vaccine. Rev Soc Bras Med Trop 2002; 35:177-80; PMID:12011927; http://dx.doi. org/10.1590/S0037-86822002000200008.

30. Carneiro M, Lara B da S, Schimidt B, Gais L. [Overdose of yellow fever vaccine in the Southern region of Brazil]. Rev Soc Bras Med Trop 2011; 44:252-3; PMID:21552746.

31. Nascimento Silva JR, Camacho LAB, Siqueira MM, Freire $M$ de $S$, Castro YP, Maia M de L, et al.; Collaborative Group for the Study of Yellow Fever Vaccines. Mutual interference on the immune response to yellow fever vaccine and a combined vaccine against measles, mumps and rubella. Vaccine 2011; 29:632734; PMID:21640779; http://dx.doi.org/10.1016/j.vaccine.2011.05.019

32. Belmusto-Worn VE, Sanchez JL, McCarthy K, Nichols R, Bautista CT, Magill AJ, et al. Randomized, doubleblind, phase III, pivotal field trial of the comparative immunogenicity, safety, and tolerability of two yellow fever 17D vaccines (Arilvax and YF-VAX) in healthy infants and children in Peru. Am J Trop Med Hyg 2005; 72:189-97; PMID:15741556.
33. Food and Drug Administration. Toxicity grading scale for healthy adult and adolescent volunteers enrolled in preventive vaccine clinical trials. U.S. Department of Health and Human Services, 2007.

34. Caufour PS, Motta MC, Yamamura AM, Vazquez S, Ferreira II, Jabor AV, et al. Construction, characterization and immunogenicity of recombinant yellow fever 17D-dengue type 2 viruses. Virus Res 2001; 79:1-14; PMID:11551641; http://dx.doi.org/10.1016/S01681702(01)00273-8.

35. National Institute for Biological Standards and Control. WHO reference reagent. The 1 st international reference preparation for anti-yellow fever serum monkey NIBSC code: YF. Available from: http://www.nibsc. ac.uk/documents/ifu/YF.pdf; 2008 [cited 15.03.2011].

36. Hintze J. 2009. Kaysville, Utah. WWW.NCSS.COM.

37. Abramson JH. WINPEPI (PEPI-for-Windows): computer programs for epidemiologists. Epidemiol Perspect Innov 2004; 1:6; PMID:15606913; http://dx.doi. org/10.1186/1742-5573-1-6.

38. Dean AG, Sullivan KM, Soe MM. OpenEpi: Open Source Epidemiologic Statistics for Public Health, Version 2.2. www.OpenEpi.com, updated 2007/11/18, accessed 2012/05/02.

\section{Appendix}

Members of the Collaborative Group for the Yellow Fever Vaccine Dose-response Study. Bio-Manguinhos: Akira Homma, President of the Political and Strategic Council; Clinical Advisory Unit: Reinaldo M. Martins (Principal Investigator), Maria de Lourdes S.Maia, Roberto Henrique G.Farias, Gloria Regina S. Sá; Deputy Directory for Technological Development: Marcos S. Freire, Ricardo Galler; Virological Technology Laboratory: Anna
Maya Yoshida Yamamura, Luiz Fernando C. Almeida, Sheila Maria B. Lima; Quality Control Department: Maria da Luz Fernandes Leal, Darcy A. Hokama. National School of Public Health: Luiz Antonio B. Camacho.Oswaldo Cruz Institute: Rita Maria R. Nogueira. Army Biology Institute: Ricardo Aguiar V. Freire, Edson Pereira Filho. 